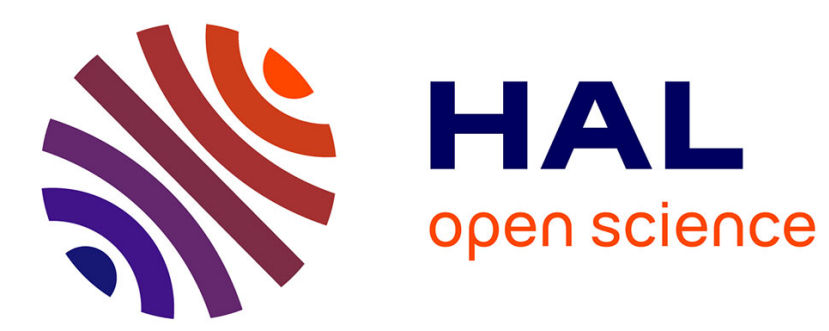

\title{
BOUND-BOUND AND BOUND-FREE CONTRIBUTIONS TO THE ABSORPTION SPECTRUM OF (H2O)-30
}

P. Campagnola, D. Lavrich, M. Johnson

\section{- To cite this version:}

P. Campagnola, D. Lavrich, M. Johnson. BOUND-BOUND AND BOUND-FREE CONTRIBUTIONS TO THE ABSORPTION SPECTRUM OF (H2O)-30. Journal de Physique IV Proceedings, 1991, 01 (C5), pp.C5-93-C5-98. 10.1051/jp4:1991511 . jpa-00250635

HAL Id: jpa-00250635

https://hal.science/jpa-00250635

Submitted on 1 Jan 1991

HAL is a multi-disciplinary open access archive for the deposit and dissemination of scientific research documents, whether they are published or not. The documents may come from teaching and research institutions in France or abroad, or from public or private research centers.
L'archive ouverte pluridisciplinaire HAL, est destinée au dépôt et à la diffusion de documents scientifiques de niveau recherche, publiés ou non, émanant des établissements d'enseignement et de recherche français ou étrangers, des laboratoires publics ou privés. 


\title{
BOUND-BOUND AND BOUND-FREE CONTRIBUTIONS TO THE ABSORPTION SPECTRUM OF $\left(\mathrm{H}_{2} \mathrm{O}\right)_{30}^{-}$
}

\author{
P.J. CAMPAGNOLA, D.J. LAVRICH and M.A. JOHNSON \\ Department of Chemistry, Yale University, 225 Prospect St., New Haven, CT 06511, U.S.A.
}

\begin{abstract}
We report absolute photodestruction cross sections for $\left(\mathrm{H}_{2} \mathrm{O}\right)_{30}^{-}$in the range $0.75<h v<4.66 \mathrm{eV}$ and recover a spectrum quite similar to that of $e_{\mathrm{aq}}^{-}$but redshifted by about $0.5 \mathrm{eV}$. The spectrum can be deconvolved into two distinct components: the low energy region below the peak in the absorption which arises from a transition to a bound excited state, and the high energy tail which arises from absorption into the electron continuum. The escape probability of the electron is unity upon excitation with more than about $0.5 \mathrm{eV}$ of excess energy above the vertical electron detachment energy of the cluster.
\end{abstract}

\section{Introduction.}

Since its discovery in $1963,{ }^{1,2}$ the detailed understanding of the hydrated electron, $e_{\mathrm{aq}}^{-}$, has stimulated an ongoing research effort. The most characteristic feature of this species is its intense optical absorption band, and the effects of temperature, phase and isotopic substitution on the appearance of this broad asymmetric spectrum are well documented. ${ }^{3,4}$ While most workers believe the ground state of the excess electron is best described by a roughly spherical wave function ${ }^{5-8}$, there has been considerable debate as to the nature of the excited state responsible for the absorption band of $e_{a q}^{-}$. For example, Kajiwara et al. ${ }^{9}$ fit the band contour to that expected for an electron bound to a spherical potential and Tuttle's ${ }^{10,11}$ analysis also seems to support the idea that the excited state is the conduction band. Alternatively, recent simulations by Berne and coworkers ${ }^{5}$ as well as Rossky and coworkers ${ }^{6-8}$ indicate the upper state consists of three bound $p$ type orbitals. In addition, through the use of ultrafast lasers, Migus et al. ${ }^{12}$ have found experimental evidence to support the two state system, which has been recently augmented by Eisenthal and coworkers ${ }^{13}$ who have found an isosbestic point in the transient absorption spectrum.

While direct observation of the excited electron in the bulk is quite difficult, gas phase cluster ions may prove to be a useful medium in which to probe the photophysics of $e_{\mathrm{aq}}^{-}$. The advantage of the cluster system is that the upper state can be directly probed by monitoring the consequence of the absorption: a bound-continuum process will be manifested simply by ejection of the electron (photodetachment) while a bound-bound absorption will first result in internal conversion of the electronic energy to vibrationally excited levels of the ground state followed by photofragmentation. To this end, we have 
constructed a tandem time of flight mass spectrometer to simultaneously monitor absolute cross sections for photodetachment and photofragmentation in the hope that these measurements will help characterize the excited state and thus the absorption band of $e_{\mathrm{aq}}^{-}$.

2. Experimental.

$\left(\mathrm{H}_{2} \mathrm{O}\right)_{n}^{-}$clusters are made by electron impact ionization of a free jet expansion of $\mathrm{H}_{2} \mathrm{O}$ in $\mathrm{Ar}$ and mass selected using standard tandem time of flight techniques. Upon excitation, the mass selected cluster will either decay via photodetachment of the electron or evaporation of neutral monomers (we rule out fluorescence since all of the photon energy is evident in the photofragmentation energetics). A typical TOF data file is shown is fig. 1 .

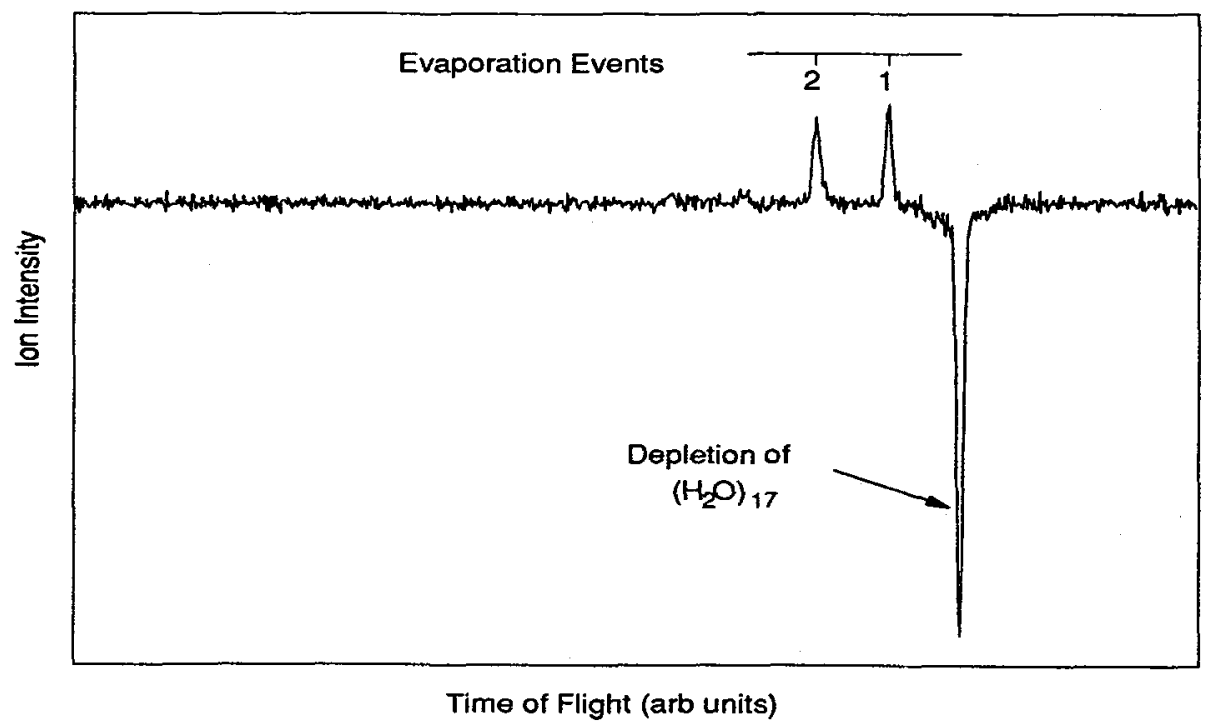

Figure 1. Raw photofragmentation data for $\left(\mathrm{H}_{2} \mathrm{O}\right)_{17}^{-}$.

The positive going peaks correspond to the evaporation of one and two monomers, and the negative peak arises from depletion of the $\left(\mathrm{H}_{2} \mathrm{O}\right)_{17}^{-}$parent cluster beam. By integrating peak intensities, we can directly measure the quantum yield for photofragmentation, $\Phi_{p}$, and infer the electron ejection channel, $\Phi_{e}=1-\Phi_{p}$.

Laser configurations used were Nd:YAG harmonics, Nd:YAG pumped dye, and difference frequency mixing of the Nd:YAG fundamental and dye beams in $\mathrm{LiIO}_{3}$. The laser beams were spatially homogenized either by far field conversion or filtering through 
a pinhole. The resulting Gaussian beams were expanded and the central lobe was isolated for the experiment. Measurement of the laser fluence and ion beam depletion establish total photodestruction cross sections, $\sigma_{0}(h v)$ and an "absorption spectrum" can then be obtained from cross section measurements taken at several discrete photon energies. The resulting spectrum can be deconvolved into its respective photofragmentation and photodetachment cross sections through $\sigma_{0}(h v) \Phi_{p}(h v)$ and $\sigma_{0}(h v) \Phi_{e}(h v)$, respectively. In addition, a time of flight electron spectrometer was used to obtain the photoelectron spectra of these species.

\section{Results}

3a) Photoelectron Spectroscopy and the cluster absorption band. To help characterize the excited state of the $\left(\mathrm{H}_{2} \mathrm{O}\right)_{n}^{-}$clusters, it is illustrative to compare the photoelectron spectrum with the absorption band of a given cluster. The photoelectron spectrum ${ }^{14}$ for $\left(\mathrm{H}_{2} \mathrm{O}\right)_{30}^{-}$is displayed along with the absorption band in fig. 2 .

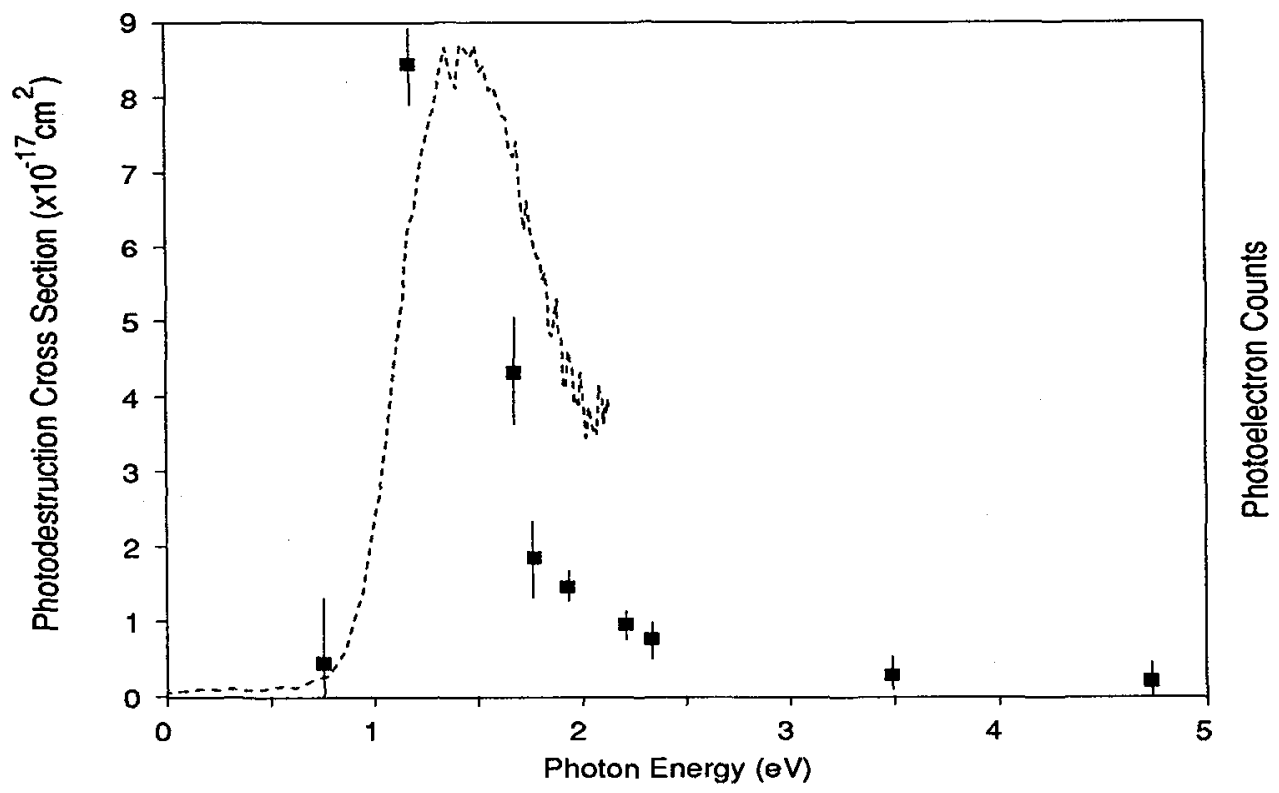

Figure 2. Absorption spectrum of $\left(\mathrm{H}_{2} \mathrm{O}\right)_{30}^{-}(\boldsymbol{\square})$ plotted along with the photoelectron spectrum (dotted line).

The width and overall envelope of the absorption band resembles the photoelectron spectrum but is peaked at slightly lower energy $\left(\mathrm{E}_{\max }=1.16 \mathrm{eV}\right)$ than the peak in the photoelectron spectrum which corresponds to the vertical electron detachment energy 
(VDE) of the cluster $\left(\mathrm{E}_{\mathrm{VDE}}=1.4 \mathrm{eV}\right)$. These similarities suggest that the excited state lies very near the electron continuum with the upper state at least somewhat bound at the geometry of the anion. Interestingly, Jortner and coworkers ${ }^{15}$ have anticipated the correlation between the absorption maximum and the VDE for the case where the electron resides in a surface state configuration.

3b) Electron Escape Probability and the Absorption Spectrum. To further ascertain the role of the continuum in the optical transition, the quantum yield for electron ejection, i.e. the electron escape probability, was examined as a function of excitation energy. In figure 3 , the absorption band for $\left(\mathrm{H}_{2} \mathrm{O}\right)_{30}^{-}$(fit with the same functional form ${ }^{3}$ as $e_{\mathrm{aq}}^{-}$) is presented along with the escape probability.

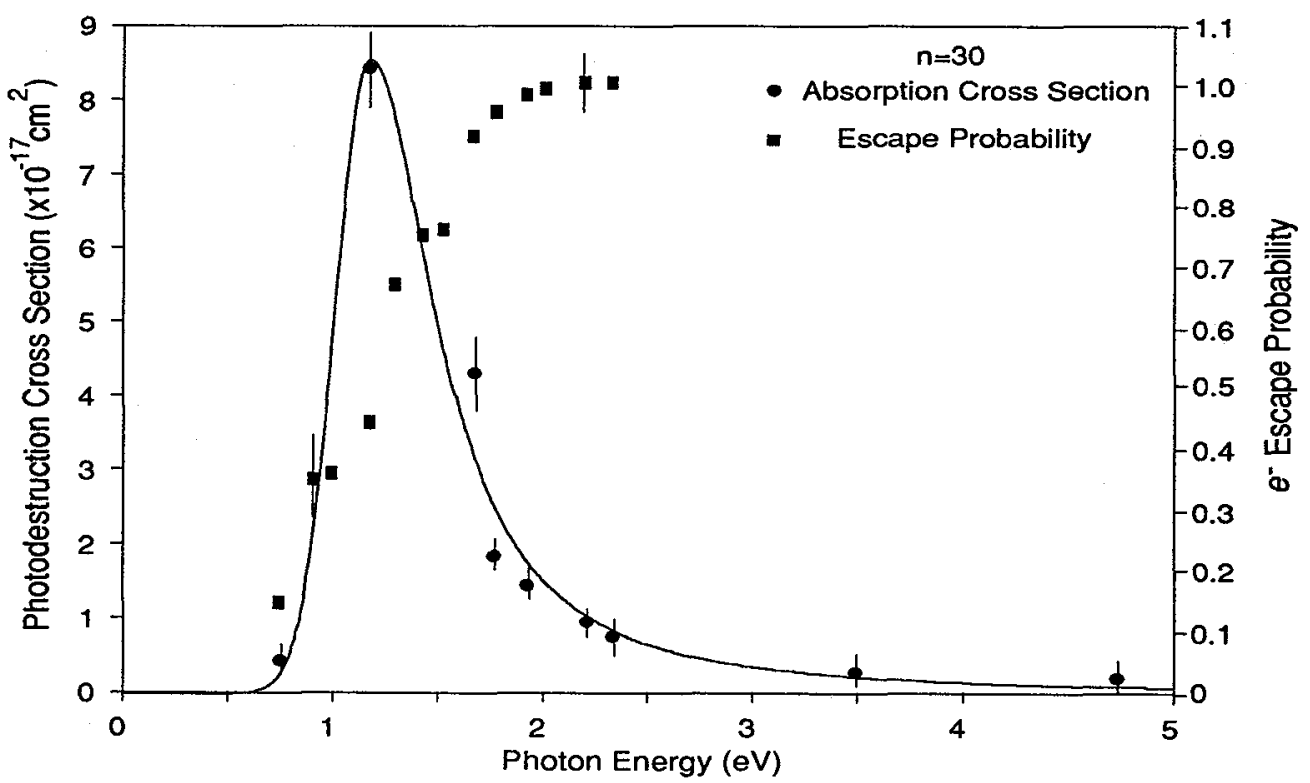

Figure 3. Absorption spectrum of $\left(\mathrm{H}_{2} \mathrm{O}\right)_{30}^{-}(-)$displayed with the electron escape probability (ㅁ)

It is apparent that as the excitation energy is raised, the electron ejection channel increasingly becomes the dominant decay channel. At the VDE the escape probability is approximately $50 \%$ and above $1.7 \mathrm{eV}$ detachment is the only channel observed. 
3c) Absolute cross sections for photofragmentation and photodetachment of $\left(\mathrm{H}_{2} \mathrm{O}\right)_{30}^{-}$. The absolute cross sections for photodetachment and photofragmentation are shown below in fig. 4, where the open markers $(O, \square)$ are approximations obtained from accurate quantum yield measurements combined with interpolated values for the absorption cross section.

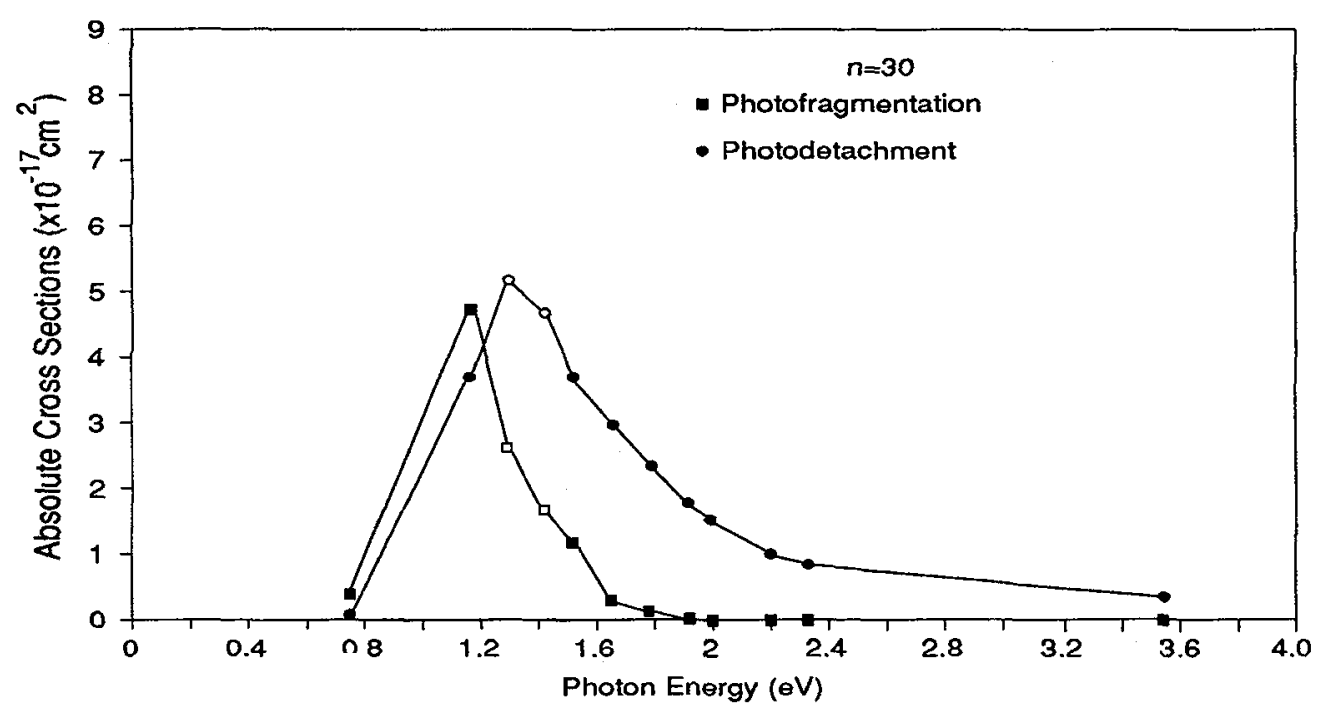

Figure 4. Absolute photofragmentation and photodetachment cross sections $(\mathbf{m , \bullet})$ for $\left(\mathrm{H}_{2} \mathrm{O}\right)_{30}^{-}$.

Near the absorption threshold, there is a strong competition between the decay channels, with the photofragmentation pathway initially carrying most of the absorption cross section. However, the high energy tail of the spectrum is dominated by electron ejection.

\section{Discussion and Conclusions.}

Utilizing $\left(\mathrm{H}_{2} \mathrm{O}\right)_{30}^{-}$clusters, we have obtained an absorption spectrum quite similar to that of $e_{\mathrm{aq}}^{-}$and have taken advantage of gas phase techniques to probe the excited state of the optical transition. Figure 4 indicates the absorption band consists of two distinct components: a bound-bound contribution manifested by photofragmentation and a boundcontinuum region observed as ejection of the excess electron. The bound-bound contribution is relatively narrow and appears very similar to the absorption band calculated for $n=32$ by Landman and coworkers ${ }^{16}$ for surface states. Note that this low 
energy "bound state" may arise from excitation of the electron which has insufficient kinetic energy to escape the cluster, i.e. the thermalization length of the electron is than less than the physical size of the cluster. ${ }^{17}$ The bound-free component is asymmetric, and displays a broad high energy tail similar to that of $e_{\mathrm{aq}}^{-}$. The cause of this tail in solution has long been speculated upon and analysis of the cluster absorption band indicates this tail is mainly due to excitation into the continuum. If the cluster absorption band is a valid model for the bulk, it seems the optical absorption band cannot be attributed solely to either a bound-bound or bound-free process but to a hybrid of the two: however, the relationship between the electron continuum of $\left(\mathrm{H}_{2} \mathrm{O}\right)_{30}^{-}$and the conduction band of the bulk is at present unclear and we hope this work will stimulate further theoretical research to clarify this issue.

Acknowledgements. We are grateful to the National Science Foundation for support of this research under Grants CHE-8910782 and CHE-8657511.

References.

(/1/ KEENE, J.P., Nature 197 (1963) 47.)

(/2/ BOAG, J.W. and HART, E.J., Nature 197 (1963) 45.)

(/3/ JOU, F.-Y., and FREEMAN, G.R., J. Phys. Chem. 83 (1979) 2383.)

(/4/ WARMAN, J.M., KUNST, M. and JONAH, C.D., J. Phys. Chem. 87 (1983) 4292.)

(/5/ WALlQVIST, A, MARTYNA, G., and BERNE, B.J., J. Phys. Chem. 92 (1988) 1721).

(/6/ SCHNITKER, J. and ROSSKY, P.J., J. Chem. Phys. 86 (1987) 3471.)

(/7/ ROSSKY P.J. and SCHNITKER, J., J. Phys. Chem. 92 (1988) 4277.)

(/8/ MOTAKABBIR, K.A., SCHNITKER, J., and ROSSKY, P.J., J. Chem. Phys. 90 (1989) 691.)

(/9/ KAJIWARA, T., FUNABASHI, K, and NALEWAY, C., Phys. Rev. A 6 (1972) 808.)

(/10/ GOLDEN, S. and TUTTLE, T.R. Jr., J. Chem. Soc. Faraday Trans. II 75 (1979) 474.)

(/11 TUTTLE, T.R. Jr., GOLDEN, S. and ROSENFELD G., Radiat. Phys. Chem. 32 No. 3 (1988) 525.)

(/12/ MIGUS, A., GAUDUEL, Y., MARTIN, J.L., and ANTONETTI, A., Phys. Rev. Lett. 58 (1987) 1559.)

(/13/ LONG, F.H., LU, H.and EISENTHAL, K.B., Phys. Rev. Lett. 64 (1990) 1469.)

(/14/ CAMPAGNOLA, P.J., LAVRICH, D.J., DELUCA, M.J., and JOHNSON, M.A., J. Chem. Phys. 94 (1991) 5240.)

(/15/ JORTNER, J., LANDMAN, U., and BARNETT, R.N., Chem. Phys. Lett. 152 (1988) 353.)

(16/ BARNETT, R.N., LANDMAN, U., MAKOV, G., and NITZAN, A., J. Chem. Phys. 93 (1990) 6226.)

(/17/ KONOVALOV, V.V., RAITSIMRING, A.M., and Tsvetkov, Yu. D., Radiat. Phys. Chem. 32 (1988) 623.) 